\title{
Hierarchical segmentation-based software for cover classification analyses of seabed images (Seascape)
}

\author{
Núria Teixidó ${ }^{1,2,3, *}$, Anton Albajes-Eizagirre ${ }^{4}$, Didier Bolbo $^{5}$, Emilie Le Hir ${ }^{6}$, \\ Montse Demestre ${ }^{2}$, Joaquim Garrabou ${ }^{2}$, Laurent Guigues ${ }^{7}$, Josep-Maria Gili ${ }^{2}$ \\ Jaume Piera ${ }^{8}$, Thomas Prelot $^{5}$, Aureli Soria-Frisch ${ }^{4}$ \\ ${ }^{1}$ Centre d'Estudis Avançats de Blanes (CEAB-CSIC), Accés Cala Sant Francesc 14, 17300 Blanes, Girona, Spain \\ ${ }^{2}$ Institut Ciències del Mar (ICM-CSIC), Passeig Marítim de la Barceloneta 37-49, 08003 Barcelona, Spain \\ ${ }^{3}$ Departament d'Ecologia, Facultat Biologia, Universitat Barcelona, Avda Diagonal 645, 08028 Barcelona, Spain \\ ${ }^{4}$ Starlab, C. Teodor Roviralta n45, 08022 Barcelona, Spain \\ ${ }^{5}$ Institut Géographique National IGN-Laboratoire MATIS, 2/4, av. Pasteur, 94165 Saint-Mandé, France
}

${ }^{6}$ Institut Géographique National, Parc Technologique du Canal, BP 42116, 6 av. de l'Europe, 31521 Ramonville Cedex, France

${ }^{7}$ CREATIS, UMR CNRS 5515, U 630 Inserm, INSA, 7 rue Jean Capelle, bat. Blaise Pascal, 69621 Villeurbanne Cedex, France

${ }^{8}$ Marine Technology Unit (UTM-CSIC), Passeig Marítim de la Barceloneta 37-49, 08003 Barcelona, Spain

\begin{abstract}
An important aspect of marine research is to quantify the areal coverage of benthic communities. It is technically feasible to efficiently obtain images of marine environments at different depths and benthic habitats over large spatial and temporal scales. Currently, there is a large and growing library of digital images to analyze, representing a valuable benthic ecological archive. Benthic coverage is the basis of studies on biodiversity, characterization of communities and evaluation of changes over temporal and spatial scales. However, there is still a lack of automatic or semi-automatic analytical methods for deriving ecologically relevant data from these images. We introduce a software program named Seascape to obtain semi-automatically segmented images (patch outlines) from underwater photographs of benthic communities, where each individual patch (species/categories) is routinely associated to its area cover and perimeter. Seascape is an analog to the classical and better known discipline of landscape ecology approach, which focuses on the concept that communities can be observed as a patch mosaic at any scale. The process starts with a hierarchical segmentation, using a color space criteria adapted to the problem of segmenting complex benthic images. As an endproduct, we obtain a set of images segmented into classified homogenous regions at different resolution levels (hierarchical segmentation). To illustrate the versatility and capacity of Seascape, we analyzed 4 digital images from different habitats and depths: coral reefs (Pacific Ocean), coralligenous communities (NW Mediterranean Sea), deep-water coral reefs (NW Mediterranean Sea) and the Antarctic continental shelf (Weddell Sea). The development of this semi-automatic outline tool and its use for classification constitute an important step forward in the analysis and processing time of underwater seabed images at any scale.
\end{abstract}

KEY WORDS: Area cover - Benthic communities - Digital photography - Image analysis · Hierarchical segmentation Resale or republication not permitted without written consent of the publisher

\section{INTRODUCTION}

Characterizing and quantifying sessile marine species (macroalgae, seagrasses and invertebrates) that occupy benthic substrate is a fundamental aspect of marine benthic research from shallow sublittoral habi- tats to continental shelves and the deep sea (Hughes \& Jackson 1985, Genin et al. 1986, Sebens 1986, Fosså et al. 2002). This essential information is the basis of studies on biodiversity, characterization of communities, evaluation of changes over spatial and temporal scales and benthic ecosystem health (e.g. Mergner \& Schuh- 
macher 1985, Connell et al. 1997, Teixidó et al. 2007, Selig \& Bruno 2010). Moreover, the effect of benthic coverage and composition regarded as biological substrate influences fish and mobile invertebrate distributions, abundances and species richness and also provides critical resources such as food, shelter and living space (Bell \& Galzin 1984, Harmelin-Vivien et al. 1995, Syms \& Jones 2000, Costello et al. 2005). The global alteration and loss of benthic coverage have lead to dramatic declines in animal diversity and abundance in all marine ecosystems (Fosså et al. 2002, Hughes et al. 2003, Halpern et al. 2008). We have developed the program Seascape as a response to the greater use of underwater digital photos combined with the increasing need to better understand ecosystem function, change, health and services. This combination produces a growing demand for automatic or semiautomatic analytical techniques that yield rapid and accurate estimates of benthic coverage and composition from complex seabed images.

In recent decades, our understanding of marine benthic communities has improved substantially owing to the development of new technologies to acquire highresolution underwater seafloor images (e.g. Ewing et al. 1967, Torlegård \& Lundalv 1974, Corliss et al. 1979, Gutt et al. 1996, Clarke 2003, Bailey et al. 2007, Lirman et al. 2007, Bowen et al. 2009, Shortis et al. 2009). This includes the use of manual image equipment (digital still and video cameras) operated by SCUBA divers and remote imaging technology in deep waters, such as remotely operated vehicles (ROVs), autonomous underwater vehicles (AUVs), landers equipped with cameras for long-term observations and a variety of other still camera systems. The use of such imaging techniques provides a nondestructive view of benthic community structure with high resolution over large spatial and temporal scales. Currently, there is a large and growing library of digital images to analyze that represents a valuable benthic ecological archive. Various procedures of underwater sampling and surveys have been evaluated for advantages and disadvantages when used to estimate cover of sessile marine organisms (e.g. Loya 1972, Chiappone \& Sullivan 1991, Foster et al. 1991, Meese \& Tomich 1992, Dethier et al. 1993, Benedetti-Cecchi et al. 1996, Nadon \& Stirling 2005). These studies identified the optimal compromise in terms of repeatability, precision, replication and costefficiency for estimating areal coverage. Traditional methods for measuring cover of benthic species and/or different ecologically relevant categories include manual selection techniques that outline the area of interest (Dodge et al. 1982, Jaap 1996). The advances in image analysis technology have opened a range of new applications to measure cover of organisms, manually or semi-automatically, such as (1) the public domain im- age application NIH Image (U.S. National Institutes of Health, http://rsb.info.nih.gov/nih-image), (2) the copyrighted software Adobe ${ }^{\circledR}$ Photoshop ${ }^{\circledR}$ and interactive color segmentation methods (Bernhardt \& Griffing 2001), (3) the use of GIS (Garrabou 1998, Teixidó et al. 2002) and (4) the public software Coral Point Count with Excel extensions (CPCe) (Kohler \& Gill 2006). However, these image-based methods involve timeconsuming processing and/or individual patch manual analysis. Overall, there is still a lack of rapid analytical methods to obtain ecologically relevant data from seabed images and a need for improved methods for assessing areal coverage.

Here, we introduce a novel, image-based analysis software (Seascape) designed to obtain semi-automatically segmented images (homogenous regions) from underwater photographs of benthic communities, where each individual patch (e.g. species, functional groups, substratum types or any sessile cover categories) is routinely associated to its areal cover and perimeter. Image segmentation consists of dividing a digital image into homogenous regions or objects according to a particular perceptual feature, such as homogeneity in color tone. Seascape is an analog to the classical and better known discipline of landscape ecology approach, which focuses on the notion that communities can be observed as a patch mosaic at any scale. We first present the development of Seascape as a tool to efficiently quantify areal cover and perimeter of individual patches. Secondly, we demonstrate the versatility of Seascape by analyzing digital images from different habitats and depths (coral reefs, coralligenous communities, deep-water coral reefs and polar communities), showing different patterns of patch complexity at different sampling areas. Finally, we evaluate the precision and processing time of Seascape for analyzing cover area of selected patches by comparing it with other software.

\section{MATERIALS AND METHODS}

Overview. Seascape is a simple, robust and high resolution software that is based on hierarchical segmentation algorithms (Guigues 2003, Guigues et al. 2006). Seascape consists of 2 main components: a graphical user interface and the core program (written in $\mathrm{C}++$ ), which contains libraries that are invoked during the execution of a run. Two main libraries involved are Lgl (an image analysis library) and SxS (Segmentation $\times$ Scale: segmentation library) (Guigues 2003, Guigues et al. 2006). The features of Seascape include: (1) multiplatform, open source software, which can be installed on different operating systems (mainly GNU/Linux, MS Windows [XP/Windows 7] and easily 
portable to Macintosh), (2) accepts many common formats, such as TIFF, JPEG, PNG and BMP, as the image input, (3) flexible species/category list database management through MS Excel spreadsheet files (e.g. species names, functional groups, complex of benthic forms, bare space, 'not readable area' categories), (4) hierarchical segmentation of grey and color images, (5) dynamic selection of working segmentation scales, (6) flexible colour-labelling code management through colour maps for species/categories, (7) easy image scaling and calibration options, (8) powerful and usable segmenting interface with selectable zoom and navigation window, (9) friendly labeling and classification of polygons of the segmented image, (10) automatic descriptors for individually classified polygons (planar area and perimeter), (11) automatic generation of export data (separately or included in previous datasheets) in Excel and ASCII files, with different options for further statistical analyses (region, locality, date, depth) and (12) exporting classified images into bitmap (BMP) and TIFF files. Seascape is an opensource platform and the compiled software, source code, developer guide and user manual are available online (www. seascapesoft.org).

Hierarchical segmentation. Image segmentation starts by dividing a digital image into homogenous regions or objects according to a particular perceptual feature, such as homogeneity in color tone. Hierarchical segmentation algorithms simultaneously analyze the image at several different scales of analysis. Their output is not a single partition, but a hierarchy of regions or data structure that captures different partitions for different scales of analysis (Guigues 2003, Guigues et al. 2006, Trias-Sanz 2006). The algorithm starts with an initial oversegmentation (e.g. segmenting almost each pixel on a different region) and uses this level as a base for the construction of subsequent significant levels.

The segmentation process is guided by an energy variable of the form:

$$
E=D+\lambda C_{1}
$$

where $D$ is a measure of goodness of fit (how well the segmentation fits to the original image; better fits give lower values of $D$ ), $C$ is a measure of segmentation complexity (less complex solutions give lower values of $C$ ) and $\lambda$ is a dimensional parameter, the scale parameter. The parameter balances between a perfect $\lambda$ fit to the original data, consisting of 1 segmentation region for each pixel in the original image, and the simplest segmentation, consisting of a single region containing the whole image (Guigues et al. 2006) (see Fig. 1 for a graphic representation of concepts related to hierarchical segmentation). It is important to emphasize that the level of segmentation can be adjusted gradually and dynamically during the classification process, from the finest to the coarsest levels depending on the image complexity.

Accuracy of Seascape. The accuracy of the analysis is a compromise between the level of segmentation, the complexity of the image and the processing time. For example, images showing high complexity of benthic forms, such as sponges, corals, bryozoans and ascidians, will require high segmentation levels and high processing time, whereas images with low complexity, such as disturbed areas with bare space, will required lower segmentation levels and lower processing time. Moreover, the level of segmentation is a dynamic process and the user can adapt it in each particular case by using low segmentation levels in the center of a coral or sponge colony and high levels at their margins.

The performance of Seascape is strongly determined by the quality of the image because the segmentation process is based on the homogeneity of the colour tone of regions. Thus, the quality of the image in general and light quality in particular will influence the segmentation process of the image and also the capacity of the user to identify the benthic organisms. The quality of the image is a basic prerequisite for any image analysis, and optimal image quality is required (e.g. colour dominance, suspended particles) in Seascape as in any other image software.

Segmentation of benthic community images with Seascape. To illustrate the versatility and capacity of Seascape, we analyzed 4 digital images from different habitats and depths: coral reefs (Pacific Ocean), coralligenous communities (NW Mediterranean Sea), deepwater coral reefs (NW Mediterranean Sea) and the Antarctic continental shelf (Weddell Sea). See Table 1 for a complete description of the images analyzed. For each case, we imported a specific Excel file created by the user with a species/category list and the digital image (as JPEG or TIFF file) into Seascape. The basic operations (see Supplement 1 at www.int-res.com/ articles/suppl/m431p045_supp.pdf for a general overview and steps of the process) consist of: importing the species/category list file, defining the colour code (RGB, values from 1 to 255) for the species/categories, importing the digital image, performing the segmentation process, specifying image scaling and calibration, labelling segmented regions where a process converts raster data (e.g. a set of pixels) into polygonal data and calculating the metrics for each polygon (planar area and perimeter). Labelled patches are obtained by merging adjacent connected regions; thus, the number of patches as well as their cover and perimeter are independent of the segmentation level. After the image has been processed, the resulting classification attained can be exported to TIFF or BMP files (back- 
Table 1. Description of the images analyzed with Seascape

\begin{tabular}{|c|c|c|c|c|c|c|}
\hline Benthic community & Position & Depth & $\begin{array}{l}\text { No. of } \\
\text { pixels }\end{array}$ & $\begin{array}{l}\text { Image } \\
\text { format }\end{array}$ & $\begin{array}{c}\text { Area } \\
\text { analyzed }\end{array}$ & $\begin{array}{l}\text { Description of the } \\
\text { underwater photograph analyzed }\end{array}$ \\
\hline \multicolumn{7}{|l|}{ Coral reefs } \\
\hline $\begin{array}{l}\text { Kingman reef, Northern Line } \\
\text { Islands, Pacific Ocean }\end{array}$ & $6^{\circ} 24^{\prime} \mathrm{N}, 162^{\circ} 24^{\prime} \mathrm{W}$ & $10 \mathrm{~m}$ & $720 \times 540$ & JPEG & $0.54 \mathrm{~m}^{2}$ & $\begin{array}{l}\text { High coverage of reef-building } \\
\text { stony corals (e.g. Acropora valida, } \\
\text { Acropora spp., Fungia scutaria, } \\
\text { Pocillopora meandrina, Porites } \\
\text { sp.), crustose coralline algae } \\
\text { (CCA) and macroalgae (Halimeda } \\
\text { opuntia) }\end{array}$ \\
\hline \multicolumn{7}{|l|}{ Coralligenous community } \\
\hline $\begin{array}{l}\text { Temperate rocky benthic } \\
\text { community, Riou Archipelago, } \\
\text { NW Mediterranean Sea }\end{array}$ & $43^{\circ} 28^{\prime} \mathrm{N}, 5^{\circ} 64^{\prime} \mathrm{E}$ & $26 \mathrm{~m}$ & $800 \times 532$ & JPEG & $578 \mathrm{~cm}^{2}$ & $\begin{array}{l}\text { High coverage of different species } \\
\text { of sponges (e.g. Axinella damicor- } \\
\text { nis, Crella pulvinar, Dyctionella }\end{array}$ \\
\hline \multirow{2}{*}{\multicolumn{2}{|c|}{ Source: Garrabou \& Teixidó (2007) }} & & & & & $\begin{array}{l}\text { sp., Dysidea avara [pallescens], } \\
\text { Haliclona fulva, Petrosia ficifor- } \\
\text { mis, Pleraplysilla spinifera, } \\
\text { Raspaciona aculeata), corals (e.g. } \\
\text { Corallium rubrum, Hoplangia } \\
\text { durotrix, Leptopsammia pruvoti) } \\
\text { and ascidians (Aplidium fuscum) }\end{array}$ \\
\hline & & \multicolumn{5}{|c|}{ Deep-water coral reefs } \\
\hline $\begin{array}{l}\text { Cap de Creus Canyon, } \\
\text { NW Mediterranean Sea }\end{array}$ & $42^{\circ} 23^{\prime} \mathrm{N}, 03^{\circ} 19^{\prime} \mathrm{E}$ & $250 \mathrm{~m}$ & $900 \times 598$ & JPEG & $0.37 \mathrm{~m}^{2}$ & $\begin{array}{l}\text { High coverage of cool-water coral } \\
\text { Madrepora oculata on hard } \\
\text { substrate (boulders) }\end{array}$ \\
\hline \multicolumn{7}{|l|}{ Antarctic continental shelf } \\
\hline $\begin{array}{l}\text { Kapp Norvegia, } \\
\text { Weddell Sea }\end{array}$ & $71^{\circ} 0^{\prime} \mathrm{S}, 11^{\circ} 0^{\prime} \mathrm{W}$ & $154 \mathrm{~m}$ & $1000 \times 938$ & TIFF & $1 \mathrm{~m}^{2}$ & $\begin{array}{l}\text { High coverage by different } \\
\text { groups of benthic suspension }\end{array}$ \\
\hline Source: Gutt \& Teixidó (1999) & & & & & & $\begin{array}{l}\text { feeders: mainly hexactinellid } \\
\text { sponges (Rossella nuda), } \\
\text { demosponges (Cinachyra } \\
\text { barbata, C. antarctica), } \\
\text { gorgonians, bryozoans and } \\
\text { compound ascidians (Polysyncra- } \\
\text { ton trivolutum) }\end{array}$ \\
\hline
\end{tabular}

ground set to black and each classified polygon to the corresponding selected labelling colour). The data are automatically assembled into an Excel or ASCII file containing information on region, locality, date, depth, image identification, species name, polygon identification, species identification, area and perimeter. The first 4 fields are optional. The user can choose to export the data to an existing Excel file for statistical analysis (e.g. all the data from several images of the same transect in the same file). Data (cover area and perimeter) are calculated for each patch labelled; thus, each patch will have information on species, area cover and perimeter. These values can be used for further analyses of biodiversity or complexity of patch forms.

Segmentation parameters: base segmentation threshold, energy complexity and working scale levels. Before segmenting an image to quantify cover area, Seascape requires the user to set values for 3 segmentation parameters: base segmentation threshold, energy complexity, and working scale levels, which affect the segmentation algorithm, the RAM usage and the computational speed. Specifically, base segmenta- tion threshold (values range from 1 to 50) is related to the division of the images in small regions. The lower the value, the more strict the criteria will be and, thus, the finer the segmentation. Lower values demand higher RAM usage. Energy complexity (values range from 1 to 32) is involved in the computational speed of the algorithm. The higher this value is set, the more computationally expensive the segmentation will be. Working scale levels (values range from 1 to 20) are related to the number of segmentation scale levels that the application will work with. For each scale level, the program has to create a segment image. For example, a value of 5 will represent 5 intermediate segmented images for each image to be analyzed. The lower the value, the lower is the RAM usage.

We highly recommend working with images with an intermediate number of pixels (e.g. approximately 1000 $\times 900$ pixels) and the default segmentation values (e.g. working scale levels of 10). It is more relevant to have a standard image of $1000 \times 900$ pixels, to choose a working scale levels of 10 to 15 (meaning 10 to 15 intermediate images) and to dynamically adjust the optimal 
level of segmentation rather than to have a large image (e.g. $3347 \times 2276$ pixels) with a working scale of 3 to 5 .

We segmented the 4 images with the following default values of segmentation parameters: base segmentation threshold $=15$, energy complexity $=1$ and working scale levels $=10$. This combination of attributes created the optimal grouping of segments and resource demands for the computation process. After this step, each image was analyzed based on a specific and dynamic 'segmentation level' depending on the complexity of each individual patch and image. Once the 4 images were segmented and classified individually, we estimated the cover area of each patch for each species and sessile cover categories.

Comparison of precision and time with other software programs. We selected individual patches of 4 species/categories to compare precision of cover area (by comparing SEs) (Andrew \& Mapstone 1987,

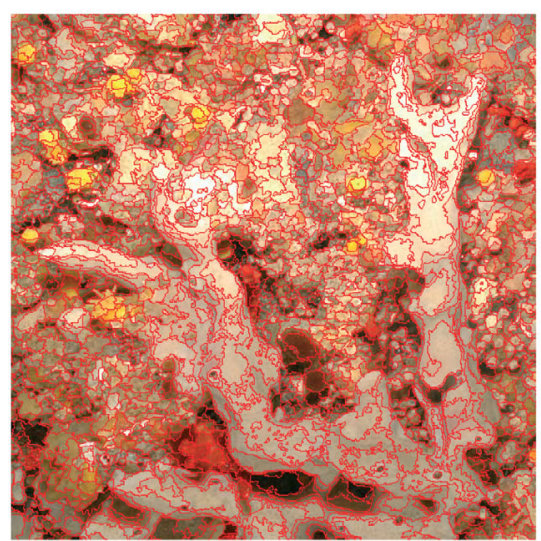

$+$

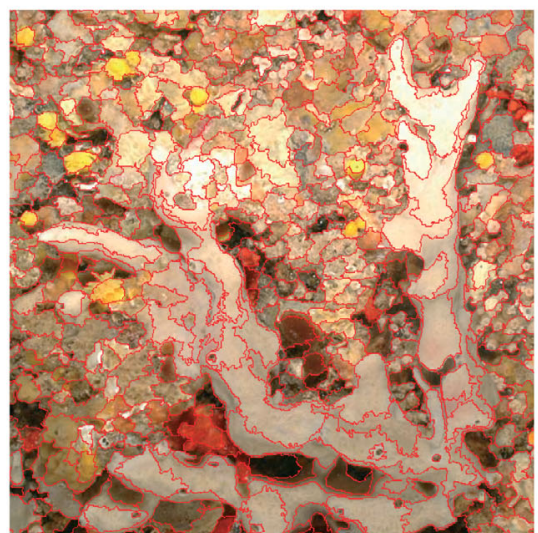

Segmentation level

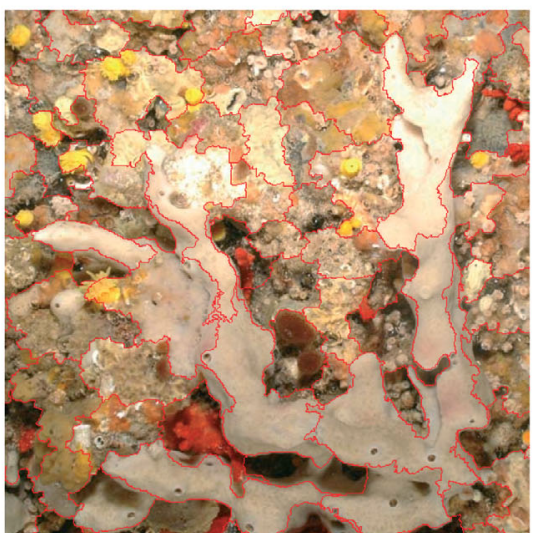

$-$

Fig. 1. Graphic representation of concepts related to hierarchical segmentation. The figure shows partitions of an image at 3 different scales of segmentation. The partition on the left has the lowest $\lambda$ and shows the finest level of detail (initial oversegmentation of the image); the partition on the right has a higher $\lambda$ and a simpler level of detail (containing only few cells for the whole image)

A

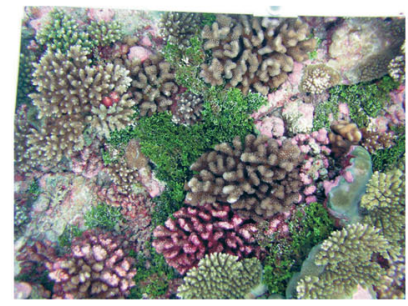

Underwater photographs

B

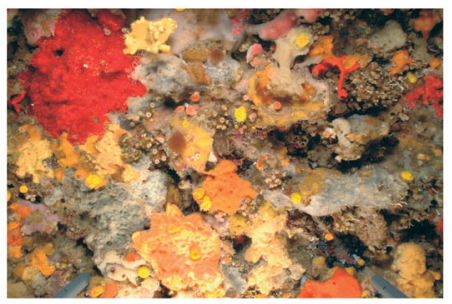

C

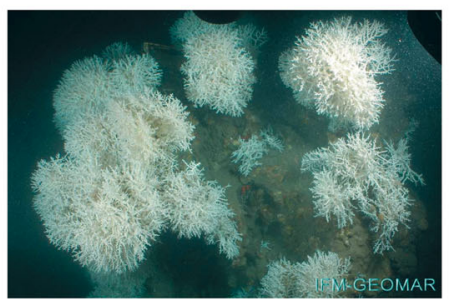

D

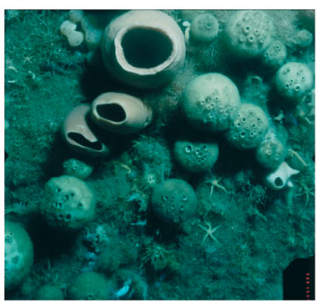

Segmentation and cover classification analyses using Seascape
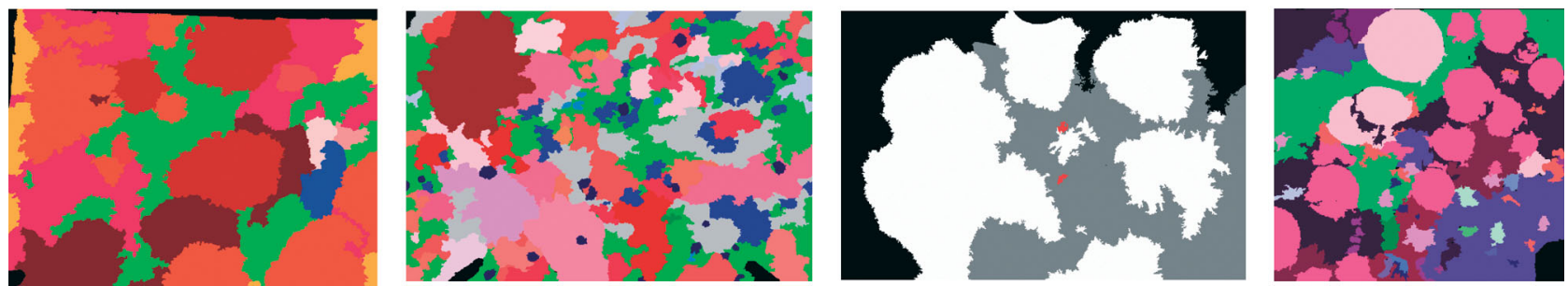

Fig. 2. Underwater photographs of different benthic communities and the images classified into cover species/categories using Seascape software. (A) Coral reef at Kingman Reef (Pacific Ocean), depth $=10 \mathrm{~m}$, total area $=0.54 \mathrm{~m}^{2}$. (B) Coralligenous community at Riou Archipelago (NW Mediterranean Sea), depth $=26 \mathrm{~m}$, total area $=578 \mathrm{~cm}^{2}$. (C) Cool-water corals at Cap de Creus Canyon (NW Mediterranean Sea), depth $=250 \mathrm{~m}$, total area $=0.37 \mathrm{~m}^{2}$. (D) Antarctic continental shelf benthos (SE Weddell Sea), depth $=160 \mathrm{~m}$, total area $=1 \mathrm{~m}^{2}$. Reproduced with permission from J. Smith, Scripps Institution of Oceanography, for image (A) and from the ICM-CSIC JAGO-Team/IFM-GEOMAR for image (C) 
Benedetti-Cecchi et al. 1996) and mean processing time obtained with different software frequently used in marine image analyses. The sampling design included 2 factors: (1) 'Software', fixed, with 3 levels: Seascape, CPCe, Image J; and (2) species, fixed, with 4 levels: Ircinia oros, Parazoanthus axinellae, Rossella sp. and complex of bryozoans belonging to the Cellarinella genus. The patches selected for this study represented a combination of size (small/large) and complexity of forms (circular/irregular): I. oros (Mediterranean sponge, patches of circular shape, sizes of 20 to $40 \mathrm{~cm}^{2}$ ), $P$. axinellae (Mediterranean zoanthid coral, irregular and complex forms, size $=20$ to $80 \mathrm{~cm}^{2}$ ), Rossella sp. (Antarctic sponge, patches of circular shape, size $=200$ to $400 \mathrm{~cm}^{2}$ ) and a complex of rigid bryozoans of Cellarinella spp. (Antarctic bryozoans, patches of irregular shape, size $=800$ to $1500 \mathrm{~cm}^{2}$ ). Three replicated patches were analyzed for each species. Nonparametric ANOVA (PERMANOVA, Anderson 2001a,b) was performed to compare precision and time among the 3 software programs and species. When appropriate, pair-wise comparisons were also done with a $t$-test and 9999 permutations of the raw data. The analyses were performed with PERMANOVA+ for PRIMER v. 6 (Clarke \& Gorley 2006, Anderson et al. 2008).

\section{RESULTS}

\section{Versatility of Seascape}

The original underwater photographs of the 4 benthic communities and the corresponding images analyzed by Seascape are shown in Fig. 2. This is an example to show that Seascape has the capacity to analyze an array of images from different habitats characterized by high complexity of benthic forms. Using Seascape to analyze all 4 images required approximately $1.75 \mathrm{~h}$ or an average of $36 \mathrm{~min}$ per image (ranging from 10 to $50 \mathrm{~min}$ ). Seascape output data format will allow further analysis of biodiversity and patch structure complexity studies (based on area and perimeter values). A complete list of the species names for each of the 4 benthic communities analyzed and some basic statistical metrics obtained by Seascape (number of patches, mean patch size and percent cover area) is available in Supplement 2 at www.int-res.com/ articles/suppl/m431p045_supp. pdf.

For comparison we placed each species in different benthic cover categories or functional groups (see Supplement 2). For example Pocillopora meandrina was placed in the Hard coral functional group (for coral reefs), Leptopsammia pruvoti in the Hexacorals group (for coralligenous communities), Madrepora oculata in the Hexacorals group (in the deep-water coral reef community), and the Demosponge complex in the Complex group (for Antarctic benthos). For the 4 images analyzed Seascape over- and underestimated 52 and $47 \%$ of the total benthic cover categories, respectively (Table 2). However, differences in percentage of cover category values ranged from $0.04 \%$ (Octocorals category in deep-water coral reefs) to $6.1 \%$ (Complex category in Antarctic benthos), with a mean $( \pm$ SED) value of $1.5 \pm 0.4 \%$ (Table 2 ).

\section{Statistical comparisons of precision and processing time}

The results of precision and processing time for each software and species analyzed are shown in Fig. 3 and Table 3. Cover area precision was significantly different among the 3 software programs used $\left(F_{2,24}=32.7\right.$, $\mathrm{p}<0.001$ ) (Table 3). In particular, Seascape showed significantly the highest precision in calculating cover area irrespective of the species considered (mean SE value $\pm \mathrm{SED}, 2.9 \pm 0.6$ ) compared with Image $\mathrm{J}$ (mean SE value, $9.1 \pm 0.58$ ) and CPCe (mean SE value, $6.6 \pm$ 0.7 ) (pair-wise test: $t=8.3$ and $t=5.2, \mathrm{p}<0.0001$, respectively). The higher variability resulted from the category of Cellarinella spp. (big and irregular patches) with SE values of $10.9 \pm 1.5$ for Seascape, 28.1 \pm 2.1 for Image $J$ and $19.1 \pm 2$ for CPCe (Fig. 3). Precision differences resulted in a significant Software $\times$ Species interaction in the PERMANOVA (Table 3). This analysis and the pair-wise tests indicated that precision using Seascape differed significantly from the other 2 software programs for Cellarinella spp. (Table 3) (pair-wise test: $t=6.5$ and $t=5.0, \mathrm{p}<0.001$, respectively).

On average, the time needed to analyze all the patches was $18.4 \pm 1.1,37.6 \pm 3.1$ and $30 \pm 2.1 \mathrm{~s}$ for Seascape, Image J and CPCe, respectively (Fig. 3). These differences in processing time were affected by software and species but not by the interaction term (Table 3). Seascape significantly reduced the processing time by approximately $40 \%$ for all the patches in comparison with other methods (Table 3). The most significant cases were the 2 species of sponges (including small and large patches) with circular shapes. It took approximately $5 \mathrm{~s}$ to calculate cover area using Seascape in contrast to 14.8 and $11.3 \mathrm{~s}$ using Image J and CPCe, respectively (Fig. 3).

The versatility, precision and processing time of Seascape demonstrate its high performance in calculating the cover area of benthic communities (both semi-automatically and in a repeatable manner), in potentially obtaining basic ecological data for further studies, and in improving analysis time. 
Table 2. Descriptive results and versatility of Seascape in relation to other software. The software Image J was used for coral reefs, coralligenous communities and deep-water coral reefs and the GIS environment was used for Antarctic benthos (Teixidó et al. 2002). The program CPCe (Kohler \& Gill 2006) also calculates planar area within the area analysis module. However, it only allows a maximum of 20 traced areas and 6000 points traced. This limits its ability to analyze the entire image and is thus not included in this comparison. NS: number of species; NP: number of patches

\begin{tabular}{|c|c|c|c|c|c|}
\hline $\begin{array}{l}\text { Benthic community } \\
\text { Benthic category }\end{array}$ & NS & NP & $\begin{array}{c}\text { Seascape } \\
\text { cover } \\
\text { estimate } \\
(\%)\end{array}$ & $\begin{array}{c}\text { Other } \\
\text { cover } \\
\text { estimate }(\%) \\
\text { (Image } \mathrm{J} \text { or GIS) }\end{array}$ & $\begin{array}{l}\text { Observed } \\
\text { difference } \\
\quad(\%) \\
\end{array}$ \\
\hline \multicolumn{6}{|l|}{ Coral reefs } \\
\hline Hard coral & 8 & 24 & 60.7 & 61.8 & 1.1 \\
\hline Soft coral & 1 & 1 & 2.2 & 2.1 & 0.1 \\
\hline Macroalgae & 1 & 7 & 18.6 & 17.9 & 0.7 \\
\hline Crustose coralline algae & & 8 & 18.4 & 18.0 & 0.4 \\
\hline \multicolumn{6}{|l|}{ Coralligenous community } \\
\hline Sponges & 15 & 49 & 56.7 & 55.3 & 1.4 \\
\hline Hexacorals & 3 & 48 & 11.3 & 8 & 3.3 \\
\hline Octocorals & 1 & 4 & 1.6 & 1.6 & 0 \\
\hline Tunicates & 1 & 3 & 0.5 & 0.3 & 0.2 \\
\hline Complex & & 32 & 18.0 & 19.8 & 1.8 \\
\hline Bare space & & 29 & 11.7 & 10.0 & 1.7 \\
\hline \multicolumn{6}{|l|}{ Deep-water coral reefs } \\
\hline Hexacorals & 1 & 8 & 51.2 & 53.9 & 2.7 \\
\hline Octocorals & 1 & 2 & 0.12 & 0.07 & 0.04 \\
\hline Hard substrate & & 1 & 28.6 & 24.7 & 3.8 \\
\hline Not readable background & & 1 & 20.0 & 21.2 & 1.2 \\
\hline \multicolumn{6}{|l|}{ Antarctic benthos } \\
\hline Hexactinellids & 1 & 3 & 12.8 & 14.2 & 1.4 \\
\hline Demosponges & 3 & 41 & 27.5 & 30.0 & 2.5 \\
\hline Octocorals & 4 & 8 & 1.2 & 2.2 & 1 \\
\hline Bryozoans & 4 & 13 & 17.3 & 17.4 & 0.1 \\
\hline Polychaetes & 1 & 1 & 0.08 & 0.05 & 0.03 \\
\hline Holothurians & 1 & 1 & 0.2 & 0.1 & 0.1 \\
\hline Tunicates & 3 & 11 & 2.7 & 3.9 & 1.2 \\
\hline Complex & & 27 & 38.0 & 31.9 & 6.1 \\
\hline
\end{tabular}

\section{DISCUSSION}

Marine benthic environments worldwide are in serious decline as a result of the synergistic effects of overfishing, pollution, mechanical habitat destruction, introduced species and climate change (Fosså et al. 2002, Halpern et al. 2008, Jackson 2008, Levin \& Dayton 2009). In many benthic communities (e.g. corals and sponges) diversity is declining, and a clearer and more accurate understanding of areal coverage and composition and their dynamics over large spatial and temporal scales is becoming more important in benthic ecology studies. Advances in new technologies for high-resolution digital photography and image analysis software provide new opportunities for the improved collection and analysis of benthic data. One of the major advantages of Seascape is its analytical capability using still benthic image data collected by remote platforms (e.g. ROV) or SCUBA divers. Our approach represents a step forward in the study of species/categories cover and their size and complexity at any scale that can provide a basic ecological data base for the study of benthic communities. Multi-scale or hierarchical segmentation algorithm-based analysis programs, such as Seascape, allow pixels to be grouped into segments and then classified based on user-defined classes. The dynamic level of segmentation incorpo-
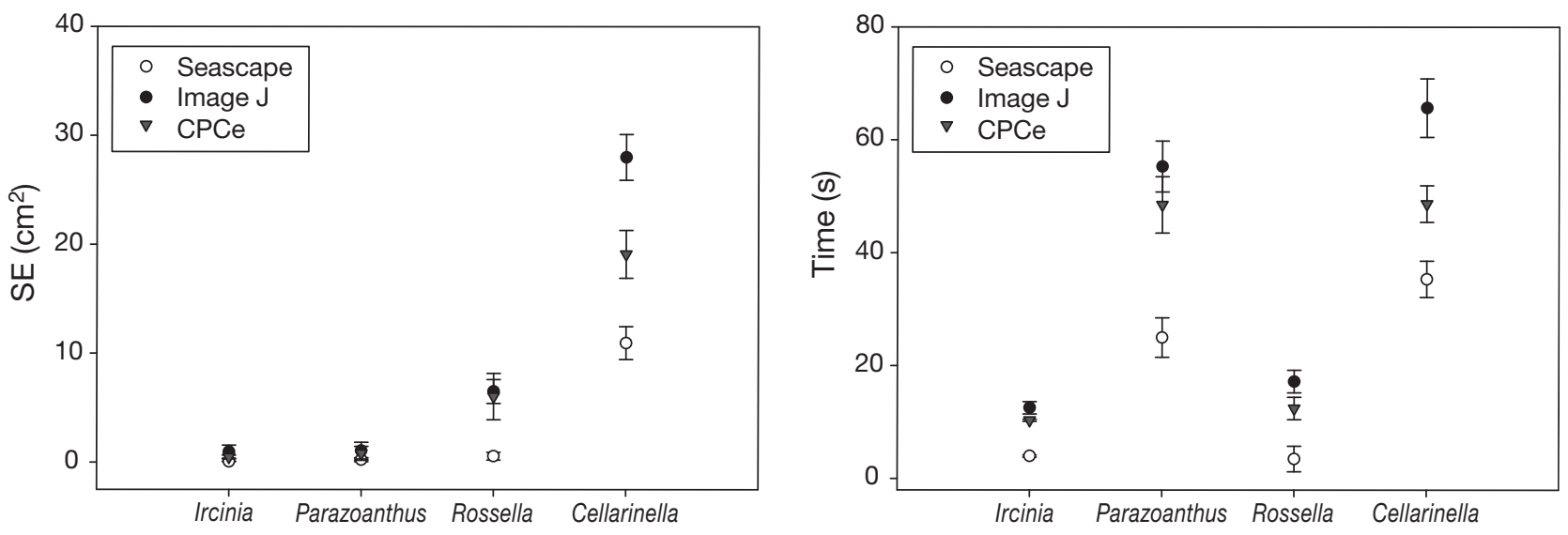

Fig. 3. Precision (as SE value) and processing time using Seascape and 2 other software programs. Data include mean values \pm SE. The patches analyzed are Ircinia oros (Mediterranean sponge, patches of circular shape, sizes range from 20 to $40 \mathrm{~cm}^{2}$ ), Parazoanthus axinellae (Mediterranean zoanthid coral, irregular and complex forms, sizes range from 20 to $80 \mathrm{~cm}^{2}$ ), Rossella sp. (Antarctic sponge, patches of circular shape, sizes range from 200 to $400 \mathrm{~cm}^{2}$ ) and a complex of rigid bryozoans of Cellarinella spp. (Antarctic bryozoans, patches of irregular shape, sizes range from 800 to $1500 \mathrm{~cm}^{2}$ ) 
Table 3. Results of PERMANOVA performed on the precision of cover area (SE) and processing time. Significant p-values $(\mathrm{p}<0.0001)$ are denoted by ${ }^{* * *}$

\begin{tabular}{|lrrrrrr|}
\hline \multirow{2}{*}{ Source variation } & df & \multicolumn{3}{c}{ Precision (SE) } & \multicolumn{3}{c|}{ Time } \\
& & MS & \multicolumn{1}{c|}{$F$} & MS & $F$ \\
\hline Software & 2 & 116.5 & $32.7^{* * *}$ & 1303.3 & $24.8^{* * *}$ \\
Species & 3 & 717.1 & $201.5^{* * *}$ & 3966.9 & $75.6^{* * *}$ \\
Software $\times$ Species & 6 & 45.4 & $12.7^{* * *}$ & 103.2 & 1.9 \\
Residual & 24 & 3.5 & & 52.4 & \\
\hline
\end{tabular}

rated in Seascape allows the user to calculate areas ranging from fine-scale segmentation, such as small corals and algae, to coarse levels of segments, such as rocky hard substrate (Fig. 2, Table 2). Moreover, based on the theory and steps described in this study, Seascape reduced the processing time of patches by approximately $40 \%$ compared with other methods (Fig. 3, Table 3). This processing time will be even less for entire images and images showing low benthic complexity patterns, such as areas affected by bottom-trawling nets, and thus it provides a good tool to rapidly and accurately evaluate affected versus nonaffected fishing areas and changes in these areas over time.

Previous techniques have been useful for estimating cover area, but have not been able to analyze semiautomatically entire images of high benthic complexity containing several different species or category types (Bernhardt \& Griffing 2001, Teixidó et al. 2002, Kohler \& Gill 2006). The capability to semi-automatically classify individual patches and calculate their area and perimeter is one of the most important benefits of this novel technique. These data are the basis for both monitoring and theoretical studies, which constitute a solid basis for management and conservation practices. Overall, differences in the precision of cover estimates as determined by Seascape and other image analyses were high when patches of the large and circular sponges Rossella sp. and the irregular and large patches of the bryozoans Cellarinella spp. were analyzed (Fig. 3, Table 3). We mainly attributed the differences observed in precision to the process of measuring cover area, which is semi-automatic and repeatable for Seascape but manual for the other software. Therefore, the high precision of Seascape is highlighted when large coverages of seabed patches are analyzed. This resolution may be even greater when the entire image is analyzed.

At a time when the study and monitoring of benthic communities are critical and their comparisons through time and across several spatial scales are necessary, analytical platforms must be precise, accurate, rapid and practical. The features of the approach described here are the capacity to segment and classify digital images of complex benthic communities in a repeatable, semi-automatic and timely manner and to perform further ecological research with the essential output data (individual polygon information of species/categories and its cover and perimeter data). We also recognize the need to continue to improve seabed image analysis, such as the automatic classification of some species or categories, automatic calculation of cover changes over time and incorporation of image analysis tools with open platforms of GIS. Finally, this study will contribute to open source software development as a platform to enhance accessibility and improve data analyses.

Acknowledgements. This work was funded by the Medchange project (Agence National de la Recherche, France), the Marie Curie Reintegration Grant Mechanisms (FP7- No. 207632), the Spanish Ministry of Science and Innovation (CTM2009-06027-E/MAR) and TOTAL Foundation (MedDiversa Project). N.T. was partially funded by I3P-CSIC and Beatriu Pinós contracts (2009-BP-B-00263). The authors thank Dr. J. Smith, Scripps Institution of Oceanography, and IFMGEOMAR for the shallow and deep-water coral reef images, respectively. We thank Drs. E. Ballesteros, J. Maragos and M. J. Uriz for taxonomic assistance. Three anonymous reviewers provided valuable comments on an earlier draft. N.T. thanks W. Arntz, P. Erwin, E. Cebrián, C. Linares, T. Teixidó, P. Peña and $\mathrm{M}$. Belzunces for critical reading and fruitful discussions.

\section{LITERATURE CITED}

Anderson MJ (2001a) A new method for non-parametric multivariate analysis of variance. Austral Ecol 26:32-46

Anderson MJ (2001b) Permutation tests for univariate or multivariate analysis of variance and regression. Can J Fish Aquat Sci 58:626-639

Anderson MJ, Gorley RN, Clarke KR (2008) PERMANOVA + for PRIMER: guide to software and statistical methods. PRIMER-E, Plymouth

Andrew NL, Mapstone BD (1987) Sampling and the description of spatial pattern in marine ecology. Oceanogr Mar Biol Annu Rev 25:39-90

Bailey DM, King NJ, Prieder IG (2007) Cameras and carcasses: historical and current methods for using artificial food falls to study deep-water animals. Mar Ecol Prog Ser 350:179-191

Bell JD, Galzin R (1984) Influence of live coral cover on coral reef-fish communities. Mar Ecol Prog Ser 15:265-274

Benedetti-Cecchi L, Airoldi L, Abbiati M, Cinelli F (1996) Estimating the abundance of benthic invertebrates: a comparison of procedures and variability between observers. Mar Ecol Prog Ser 138:93-101

Bernhardt SP, Griffing LR (2001) An evaluation of image analysis at benthic sites based on color segmentation. Bull Mar Sci 69:639-653

Bowen AD, Yoerger DR, Taylor C, McCabe R and others (2009) The Nereus hybrid underwater robotic vehicle. Underwat Technol 28:79-89

> Chiappone M, Sullivan KM (1991) A comparison of line transect versus linear percentage sampling for evaluating stony coral (Scleractinia and Milleporina) community similarity and area coverage on reefs of the central Bahamas. Coral Reefs 10:139-154 
Clarke T (2003) Robots in the deep. Nature 421:468-470

Clarke KR, Gorley RN (2006) PRIMER v6: user manual/tutorial. PRIMER-E, Plymouth

Connell JH, Hughes TP, Wallace CC (1997) A 30-year study of coral abundance, recruitment, and disturbance at several scales in space and time. Ecol Monogr 67:461-488

Corliss JB, Dymond J, Gordon LI, Edmond JM and others (1979) Submarine thermal springs on the Galápagos Rift. Science 203:1073-1083

Costello J, McCrea M, Freiwald A, Lundälv T and others (2005) Role of cold-water Lophelia pertusa coral reefs as fish habitat in the NE Atlantic. In: Freiwald A, Roberts JM (eds) Cold-water corals and ecosystems. Springer-Verlag, Berlin, p 771-805

Dethier MN, Graham ES, Cohen S, Tear LM (1993) Visual versus random-point percent cover estimations: 'objective' is not always better. Mar Ecol Prog Ser 96:93-100

Dodge RE, Logan A, Antonius A (1982) Quantitative reef assessment studies in Bermuda: a comparison of methods and preliminary results. Bull Mar Sci 32:745-760

Ewing M, Worzel JL, Vine AC (1967) Early development of ocean-bottom photography at Woods Hole Oceanographic Institution and Lamont Geological Observatory. In: Hersey JB (ed) Deep-sea photography. The Johns Hopkins Press, Baltimore, MD, p 13-41

Fosså JH, Mortensen PB, Furevik DM (2002) The deep-water coral Lophelia pertusa in Norwegian waters: distribution and fishery impacts. Hydrobiologia 471:1-12

Foster MS, Harrold C, Hardin DD (1991) Point vs photo quadrat estimates of the cover of sessile marine organisms. J Exp Mar Biol Ecol 146:193-203

Garrabou J (1998) Applying geographic information system (GIS) to study the growth of benthic clonal organisms. Mar Ecol Prog Ser 173:227-235

Garrabou J, Teixidó N (2007) Sea-bed images of permanent plots of rocky benthos at Marseille, site Riou Sud, plot R7D. doi:10.1594/PANGAEA.634001

Genin A, Dayton PK, Lonsdale PF, Spiess FN (1986) Corals on seamount peaks provide evidence of current acceleration over deep-sea topography. Nature 322:59-61

Guigues L (2003) Modèles multi-échelles pour la segmentation d'images [Multiscale analysis models for the segmentation of images]. PhD thesis, Université de CergyPontoise

Guigues L, Cocquerez JP, Men H (2006) Scale-sets image analysis. Int J Comput Vis 68:289-317

Gutt J, Starmans A, Dieckmann G (1996) Impact of iceberg scouring on polar benthic habitats. Mar Ecol Prog Ser 137: 311-316

Gutt J, Teixidó N (2004) Sea-bed photographs (benthos) along ROV profile PS48/215. doi:10.1594/PANGAEA.319903

Halpern BS, Walbridge S, Selkoe KA, Kappel CV and others (2008) A global map of human impacts of marine ecosystems. Science 319:948-952

> Harmelin-Vivien M, Harmelin JG, Leboulleux V (1995) Microhabitat requirements for settlement of juvenile sparid fishes on Mediterranean rocky shores. Hydrobiologia 300-301:309-320

Hughes TP, Jackson JBC (1985) Population dynamics and life histories of foliaceous corals. Ecol Monogr 55:141-166

Hughes TP, Baird AH, Bellwood DR, Card M and others

Editorial responsibility: Laura Airoldi,

Ravenna, Italy
(2003) Climate change, human impacts, and the resilience of coral reefs. Science 301:929-933

Jaap WC (1996) Monitoring methods for assessing coral reef biota and habitat condition. In: Crosby MP, Gibson GR, Potts KW (eds) A coral reef symposium on practical, reliable, low cost monitoring methods for assessing the biota and habitat conditions of coral reefs. NOAA Office of Ocean and Coastal Resource Management, Silver Spring, $\mathrm{MD}, \mathrm{p}$ 45-51

Jackson JB (2008) Ecological extinction and evolution in the brave new ocean. Proc Natl Acad Sci USA 105: $11458-11465$

Kohler KE, Gill SM (2006) Coral Point Count with Excel extensions (CPCe): a visual basic program for the determination of coral and substrate coverage using random point count methodology. Comput Geosci 32:1259-1269

Levin LA, Dayton PK (2009) Ecological theory and continental margins: where shallow meets deep. Trends Ecol Evol 24: 606-617

> Lirman D, Gracias N, Gintert B, Gleason A, Reid R, Negahdaripour S, Kramer P (2007) Development and application of a video-mosaic survey technology to document the status of coral reef communities. Environ Monit Assess 125: $59-73$

- Loya Y (1972) Community structure and species diversity of hermatypic corals at Eilat, Red Sea. Mar Biol 13:100-123

Meese RJ, Tomich PA (1992) Dots on the rocks: a comparison of percent cover estimation methods. J Exp Mar Biol Ecol 165:59-73

Mergner H, Schuhmacher H (1985) Quantitative analysis of coral communities of Sanganeb-Atoll (central Red Sea) I. The community structure of outer and inner reefs exposed to different hydrodynamic regimes. Helgol Meersunters 39:375-417

Nadon MO, Stirling G (2005) Field and simulation analyses of visual methods for sampling coral cover. Coral Reefs 25: 177-185

Sebens KP (1986) Spatial relationships among encrusting marine organisms in the New England subtidal zone. Ecol Monogr 56:73-96

Selig ER, Bruno JF (2010) A global analysis of the effectiveness of marine protected areas in preventing coral loss. PLoS ONE 5:e9278

Shortis MR, Harvey E, Abdo D (2009) A review of underwater stereo-image measurement for marine biology and ecology applications. Oceanogr Mar Biol Annu Rev 47:257-292

Syms C, Jones GP (2000) Disturbance, habitat structure, and the dynamics of a coral-reef fish community. Ecology 81:2714-2729

Teixidó N, Garrabou J, Arntz WE (2002) Spatial pattern quantification of Antarctic benthic communities using landscape indices. Mar Ecol Prog Ser 242:1-14

Teixidó N, Garrabou J, Gutt J, Arntz WE (2007) Iceberg disturbance and successional spatial patterns: the case of the shelf Antarctic benthic communities. Ecosystems 10: 143-158

Torlegård AK, Lundalv T (1974) Under-water analytical system. Photogramm Eng 40:287-293

Trias-Sanz R (2006) Semi-automatic rural land cover classification from high-resolution remote sensing images. $\mathrm{PhD}$ thesis, Université Paris 5

Submitted: July 19, 2010; Accepted: March 11, 2011

Proofs received from author(s): May 15, 2011 